\title{
HISTÓRIAS QUE PRECISAM SER CONHECIDAS: REFLEXIVIDADE DE PROFESSORES EM AÇÕES PLURAIS NA ESCOLA PÚBLICA
}

\section{Sheila Orbetelli}

\section{RESUMO}

Venho mostrar através deste artigo, o trabalho desenvolvido em minha sala de aula, uma $4^{\mathrm{a}}$ série, em uma escola pública municipal da periferia de Campinas. Meu objetivo, enquanto pesquisadora da reflexividade docente e da aprendizagem mediada, é buscar alternativas de "ensinagem” para superação das dificuldades que encontramos no processo de aprendizagem escolar. Entre estas dificuldades, uma das que mais me afetaram como professora, foi minha própria desmotivação, frente à necessidade diferenciada de cada aluno, em classes muito numerosas, causando assim uma diversidade representativa da comunidade escolar, dentro da sala de aula. $\mathrm{O}$ trabalho em duplas, a avaliação formativa, o estabelecimento de significação e sentido dos conteúdos, o estabelecimento de clima agradável, amistoso e harmônico, a maior interação entre alunos e professora, e também, o trabalho interdisciplinar desenvolvido através de "mini-projetos”, em paralelo com um grupo de estudos que consta como atividade do projeto, possibilitou vislumbrar novos horizontes.

\section{PALAVRAS-CHAVES}

Mediação; Reflexividade, Trabalho diversificado

\section{HISTORIES THAT NEED TO BE KNOWN: REFLEXIVE'S TEACHER IN THE PUBLIC SCHOOL}

\begin{abstract}
This article it comes to show the work developed at my classroom, a 4th grade, in a municipal public school at the city of Campinas periphery. My goal, while teaching reflection researcher and mediate learning, is to search teaching alternatives for difficult surpassing that we find at the school learning process. Between those difficulties, one that most affected me as a teacher, was my own lack of motivation, front to the different needs of each student, into very numerous rooms, causing this way a representative diversity out of the school community, inside the classroom. The work at double, the formative validation, the establishment of meaning to the subjects, as much as harmony and friendship at classroom, the interaction between students and teachers and, also, the interdisciplinary work developed trough mini-projects, at the same time with a workgroup that const as project activity., has made possible to take a look at new horizons.
\end{abstract}

\section{KEYWORDS}

Mediate; Rreflection; Diversified work.

\section{INTRODUÇÃO}

Sou professora de escola pública desde 1988. Durante este período, trabalhei com diversos desafios pedagógicos, desde a falta de condições físicas no ambiente escolar, passando por dificuldades 
PROCESSO ENSINO-APRENDIZAGEM: ALGUMAS ESPECIFICIDADES

Grupo de Pesquisa em Ensino Superior

em atingir meus alunos e objetivos pedagógicos, até chegar em dilemas e questionamentos com relação à própria escolha da profissão e razão do meu trabalho, como profissional da educação.

Sempre lecionei em classes de primeira à quarta série do ensino fundamental, exceto durante 3 anos nos quais me dediquei à direção de escolas de Ensino Fundamental e E.J.A (Educação de Jovens e Adultos).

No ano de 2003, me removi para esta escola de periferia em meu município, bairro este de origem humilde. A clientela é formada, na sua grande maioria, por filhos de operários qualificados que trabalham nas grandes empresas do município, mas também por crianças que têm seus pais em subempregos e até mesmo desempregados. Esta diversidade se apresenta com total representatividade em nossa comunidade escolar. Por conta disso, trabalhamos com diferentes níveis de aptidão, interesse, empenho, dedicação, interação, sociabilidade, prontidão e cognição em sala de aula. A diversidade é realmente muito grande e capaz até mesmo, de desnortear o trabalho pedagógico do professor despreparado para enfrentar tal dilema!

Foi exatamente isto que aconteceu comigo, quando cheguei na E.M.E.F. Padre Francisco Silva. Me vi totalmente desmotivada e despreparada frente ao trabalho que me esperava! Comecei a trabalhar de maneira tradicional, isto é, dando ênfase a fazeres pré-determinados, em modelos ritualizados e em comportamentos pré-estabelecidos por tradições, pois até então era o único modelo que conhecia!

Percebi, logo de saída, que, para aqueles alunos, o que eu oferecia era muito pouco, e sem uma noção muito clara de “como” e "porquê” iniciei meu trabalho com propostas diferentes, nas quais incluí:

- Trabalho em duplas,

- Apresentação de portfólios, como prática avaliativa,

- Estabelecimento de relações de respeito e cidadania entre os pares,

- Interação mais aprofundada entre alunos e professora,

- Estabelecimento de clima agradável e harmônico,

- Estabelecimento de significação, sentido e aplicação às propostas de atividades,

- Trabalho interdisciplinar, desenvolvido como mini-projetos.

Em paralelo às minhas tentativas de mudanças, iniciamos, na escola, um grupo de estudos, interessado em novas práticas, tendências, novos olhares para a educação, novos saberes e sabores docentes, para que pudéssemos alcançar uma real (re)significação de nossa função como educadores, e (C) ETD - Educação Temática Digital, Campinas SP, v.7 , n. esp., p.111-116 , jun. 2006 - ISSN: 1676-2592. 
também (re)significar os caminhos pelos quais passam (ou deveriam passar) o compromisso do educador com o objeto maior do seu trabalho: a aprendizagem do seu aluno.

Quando iniciamos o grupo de estudos, nomeamos o projeto de “Escola singular: ações plurais”. Como o grupo era muito grande, foi subdividido em grupos menores, que definiram seu objeto de pesquisa, entre os vários temas que foram surgindo durante as reuniões realizadas pelo grupo.

O subgrupo no qual me inclui, no início do projeto, tinha como objeto estudar o tema Trabalho Diversificado. Começamos, então, a nos questionar sobre o quê seria, como seria, para quê seria, e sobretudo, para quem seria este tal trabalho diversificado.Verificamos que se abriria um leque muito extenso de opções, ficando a inquietação: Onde, exatamente, focar o nosso olhar???

O saber ser, o saber fazer, e o saber estar, eram, em nossos conceitos, o elemento desencadeador do processo de transformação dos alunos em indivíduos com vida concreta e agentes transformadores do momento histórico em que vivem, e o mais importante: conscientes disto!

Lemos e estudamos vários textos e diferentes autores. Houve, então, uma “chuva de idéias” e o grupo decidiu focar o olhar em um aspecto mais específico deste tema, que ao nosso ver seria : Como apresentar conteúdos aos nossos alunos, de maneira diferente (que ainda iríamos buscar) dentro e fora da sala de aula?

Ao apresentar o tema à Coordenadora da pesquisa, ela nos fez ver que ainda assim, tínhamos um tema muito amplo para definir e nos ajudou a focar um pouco mais a nossa lente, foi quando decidimos trabalhar com “Tutoria e Mediação” e "Saberes docentes necessários para que a aprendizagem aconteça”, respectivamente meu objeto e de minha parceira no subgrupo.

Segundo Mentes (1997, p.13),

a aprendizagem mediada permite ao indivíduo desenvolver habilidades de pensamento eficientes, que lhe possibilitará tornar-se aprendiz independente e autônomo. Pois a aprendizagem mediada e a cognição podem fazer o trajeto da aprendizagem efetiva.

Por meio do meu foco de pesquisa, pude constatar, através da observação diária dos alunos e das leituras realizadas, muitas situações que demonstraram que a aprendizagem mediada perpassa, fundamentalmente, pela tomada de consciência do professor e que sua relação e interação com seu aluno são de importância total no sucesso deste processo.

O aprender a aprender inclui: motivação do aluno, desenvolvimento das funções cognitivas, e como já citado, a interação professor-aluno.

A equipe da universidade tem sido de fundamental importância e apoio durante as reuniões semanais, que se realizam em espaço físico cedido pela unidade escolar, com o apoio e a participação (C) ETD - Educação Temática Digital, Campinas SP, v.7 , n. esp., p.111-116 , jun. 2006 - ISSN: 1676-2592. 
de todo o corpo diretivo e pedagógico. Os coordenadores do trabalho, oriundos da universidade, têm nos orientado com sugestões de diversas nas leituras, e também têm nos assessorado na apresentação para discussão de diferentes e contrastantes teses de pensamentos pedagógicos e na elaboração e apresentação de seminários e fóruns de debates.

A Unidade Escolar tem se esmerado em proporcionar espaços e condições ideais para que o trabalho se desenvolva, tais como: disponibilidade de espaço físico para as reuniões, tempo disponibilizado para discussões, de maneira a se realizarem os encontros, sem maiores empecilhos a este trabalho, mesmo porque, a comunidade escolar representa uma das maiores interessadas na manutenção desta pesquisa, pois visa estimular a aprendizagem autônoma e liberar o potencial do aluno para que aprenda a aprender.

Meu trabalho, basicamente, se resume em realizar minhas observações e pesquisa, e aplicações dos resultados destas em minhas aulas, sempre me norteando pelos temas, discussões e conclusões as quais chegamos, após as reuniões.

Trabalho com quarta série, normalmente com classe de 35 alunos, crianças com idades entre 10 e 14 anos. Procuro levar para dentro de minha sala de aula, além dos conteúdos específicos necessários para o desenvolvimento acadêmico dos meus alunos, através de um clima agradável e de companheirismo, o que naturalmente, nem sempre é assim, pois existem momentos de conflitos, tensões e desentendimentos, presentes em toda e qualquer relação humana, mas que são rapidamente resolvidos com a boa relação já estabelecida entre as partes envolvidas.

Conforme as observações feitas, pude constatar que esta maneira diferente de trabalho perpassa pela afetividade professor-aluno, pela afinidade e aceitação entre as pessoas envolvidas na relação de troca e na tomada de consciência do aluno, de que neste momento é necessária a ajuda de um colega, precisa de uma tutoria para acompanhar e integrar o processo de aprendizagem que se desenvolve no espaço em que ele ocupa, naquele momento.

Chamo de tutoria a relação entre dois alunos ou mais, como grupo, ou dupla, solucionadora de atividades, desafios, problemas e dilemas que possam estar surgindo durante o trabalho solicitado.

Quase sempre, no princípio, eu mesma proponho as duplas, conforme avalio o desempenho dos alunos depois e um período de sondagem, no decorrer do processo, em ocasiões diversas, a partir de alguns outros critérios de organização tais como: avaliação individual, tomada de opinião sobre tema discutido, ou quando vejo necessidade de trabalho de trabalho individual, as duplas podem ser suspensas e a proposta de trabalho mudada.

(C) ETD - Educação Temática Digital, Campinas SP, v.7 , n. esp., p.111-116 , jun. 2006 - ISSN: 1676-2592. 114 


\section{PROCESSO ENSINO-APRENDIZAGEM: ALGUMAS ESPECIFICIDADES}

Grupo de Pesquisa em Ensino Superior

As duplas tendem a se formar de maneira uniforme, isto é, os “fortes” se juntam e os “menos fortes” também se juntam, aí é hora da interferência da professora novamente, pois devemos levar em conta que o trabalho de tutoria visa fazer, entre outras coisas, com que todas as crianças interajam e façam parte do grupo e do processo ensino-aprendizagem que se realiza naquela sala naquele momento histórico, e todos, com suas diferenças, fazem parte dele.

Podemos lançar mão de estratégias variadas tais como, diários de classe, que é grande aliado do professor no momento de avaliar as duplas, tendo em vista a avaliação formativa, na qual tem no erro uma valiosa ferramenta, pois nesta prática avaliativa, o professor precisa entender a verdadeira superação de reprovação, e isto se consegue com um sério compromisso com a aprendizagem do aluno.

A atitude observadora do professor também é parte importante desta prática, que auxilia a perceber as diversidades com as quais lida no seu cotidiano, e dá a ele parâmetros para interferências nas duplas. Procuro intervir nas duplas, o mínimo possível, e só o faço para garantir a execução da atividade solicitada, quando observo que os objetivos do trabalho em duplas não estão sendo alcançados, ou ainda se observo um dos alunos se beneficiando de cópias do aluno que no momento é o tutor da dupla. Também é hora de intervenção se percebo que a criança que é a tutora se prejudica, por conta de não conseguir administrar seu tempo e a sua função de tutora do colega. É de extrema importância a conscientização das duas partes da dupla de que naquele momento um deles é o tutor e o outro o que necessita de ajuda, mas que em outras ocasiões e ou atividades poderão ser invertidas as funções, em vista de que todos temos diferentes aptidões, somos diferentes em quase tudo e nem sempre, isto é, quase nunca, somos bons em tudo e em todos os momentos!

Concordo com Mentes (1997, p.13), quando ele diz que “a aprendizagem mediada permite aos indivíduos desenvolverem habilidades de pensamento eficientes que lhes possibilitem tornarem-se aprendizes independentes e autônomos”. Tenho acreditado nesta tendência educacional. Minha busca tem sido em trabalhar de maneira diferenciada nos terrenos teórico e prático, buscando transformações no próprio âmbito da escola, que é onde se desenvolve a ação do ensino-aprendizagem, tanto no aluno como no professor.

A ação educativa, passando pela afetividade, compromisso, interdisciplinaridade, a meu ver, é um caminho novo, no qual, existe luz no seu final. Este caminho se refere à possibilidade de conscientização do indivíduo, através da educação, do seu poder transformador, como ser social, vivendo neste momento e neste lugar, e com possibilidades de transformação de seu presente e do futuro de sua história e da história de sua geração. Como educadores temos que acreditar que esta possibilidade de mudança, existe! E que está, em parte, em nossas mãos! A mudança no processo 
histórico da escola, nos currículos, práticas e concepções educacionais de alunos, pais e profissionais da educação, passa pela ação educacional de cada professor.

Precisamos tentar cavar espaços para a existência de uma nova consciência política de cada cidadão em potencial, pois esta é a verdadeira “matéria-prima” do nosso trabalho em sala de aula. Trabalhamos com o futuro em potencial, que se reflete em cada aluno.

Precisamos usar a escola como espaço definitivo para a criação de uma nova ética de responsabilidade social, visando o bem comum e criando perspectivas para que isto ocorra.

Esta tem sido minha contribuição entre os meus pares, ao apresentar resultados das minhas investigações, durante reuniões, congressos e grupos de estudos que ocorrem na escola.

\section{REFERÊNCIAS}

MENTES, Mandia. Prog. de Pesq. Cognitiva-Divisão de Ensino Especializado da Universidade de Witwatersrand-Africa do Sul. São Paulo: Ed. Senac, 1997. Tradução José Francisco Azevedo.

\section{SHEILA ORBETELLI}

Pedagoga.

Professora da $4^{\mathrm{a}}$ série da EMEF

Padre Francisco Silva.

e-mail: sheilaorb@yahoo.com.br 